\title{
BMJ Open Quality Incorporating patient safety into early undergraduate medical education: teaching medical students to perform surgical time outs during anatomy
}

Abdul-Rahman M Suleiman (1) ,' Daniel Amarasinghe, ${ }^{1}$ Priya Kathuria, ${ }^{1}$
Jacob Vandel, ${ }^{1}$ Jordan Holloway, ${ }^{1}$ Kenneth Elkin, ${ }^{1}$ Paul Walker, ${ }^{2}$ Diane Levine ${ }^{3}$

To cite: Suleiman A-RM, Amarasinghe D, Kathuria $P$, et al. Incorporating patient safety into early undergraduate medical education: teaching medical students to perform surgical time outs during anatomy. BMJ Open Quality 2021;10:e001229. doi:10.1136/ bmjoq-2020-001229

- Prepublication history and additional material is published online only. To view please visit the journal online (http://dx. doi.org/10.1136/bmjoq-2020001229).

Initial pilot data at IHI National Forum (December 2017, Orlando, Florida). Data after second analysis were presented at AAMC Learn Serve Lead (November 2018, Austin, Texas).

Received 14 October 2020 Revised 26 January 2021 Accepted 28 February 2021

Check for updates

(C) Author(s) (or their employer(s)) 2021. Re-use permitted under CC BY-NC. No commercial re-use. See rights and permissions. Published by BMJ.

For numbered affiliations see end of article.

Correspondence to

Dr. Diane Levine;

dllevine@med.wayne.edu

\section{ABSTRACT}

Objectives To introduce surgical safety checklists and time outs to future physicians through early incorporation of time outs in the first year gross anatomy course. Setting The Wayne State University School of Medicine Anatomy Lab.

Participants Approximately 300 first year medical students per year participated in the intervention. Interventions An educational presentation on medical errors focusing on surgical errors was developed. Students in 2017-2018 viewed the presentation and completed two time outs, one with the first anatomy dissection and a second with the last dissection. Preintervention and postintervention surveys were completed and results compared. Students completed a second postintervention survey after the second time out. Students in 2018-2019 were asked to complete the time outs before every dissection. Time out procedure sheets were collected to determine completion rates. The intervention was further modified for academic year 2019-2020 and time out sheets were again collected.

Outcome measures Four domains of learning were surveyed: (1) major components and goals/limitations of universal protocol, (2) medical error lexicon, (3) components of a time out, and (4) confidence in completing time out checklists.

Results Postintervention surveys demonstrated significant improvement in each domain. Students found time outs easy to complete and developed confidence in performing time outs. Following a successful pilot, time outs were incorporated into every dissection. Students continued to perform this procedure despite absence of adverse consequences for not doing so.

Conclusion Students found the time outs easy to complete and developed the confidence and ability to perform a surgical time out early in their medical education. The new skills, knowledge and attitudes that these medical students have developed will hopefully improve the care they provide to patients, thereby advancing the practice of quality improvement and patient safety in the clinical setting.

\section{INTRODUCTION}

Medical error has been reported as the third leading cause of death in the USA, with an estimate of 251000 deaths annually. ${ }^{1}$ A large number of adverse events occur in the operating room and $50 \%$ of these are considered preventable. ${ }^{2}$ These errors include wrong side surgery, wrong patient surgery and wrong procedure. These may result in increased medical costs, serious injury or death. ${ }^{13}$ This has prompted the use of surgical safety checklists and time outs to reduce morbidity and mortality. ${ }^{4}$ Eleven years after the release of the WHO Surgical Safety Checklist, there has been widespread implementation of the checklist to improve patient safety. In 14 hospitals that adhered to a surgical safety checklist programme, there was a $22 \%$ reduction in postoperative surgical mortality rates. ${ }^{4}$ However, adherence to surgical checklists has been variable with studies involving direct observation indicating complete adherence between $30 \%$ and $100 \% .^{5}$

Inconsistent physician participation in patient safety has been attributed to lack of formal education in quality improvement and patient safety (QIPS). ${ }^{46}$ The majority of physicians are first exposed to QIPS during graduate medical education. ${ }^{7}$ The Association of American Medical Colleges (AAMC) has stated that the slow progress of QIPS in the clinical setting has been due to the lack of integration into the core curriculum of medical students. ${ }^{7}$ Recently, competencies for QIPS have been published by the AAMC to address these deficits. ${ }^{8}$ Exposing students early in their undergraduate medical education to the surgical safety checklist and time out may help develop values and behaviours that promote a culture of safety. We introduced these safety tools during gross anatomy dissection, a course which is delivered to all first year medical students at our institution.

\section{METHODS}

To integrate patient safety education into the medical school curriculum, students from 


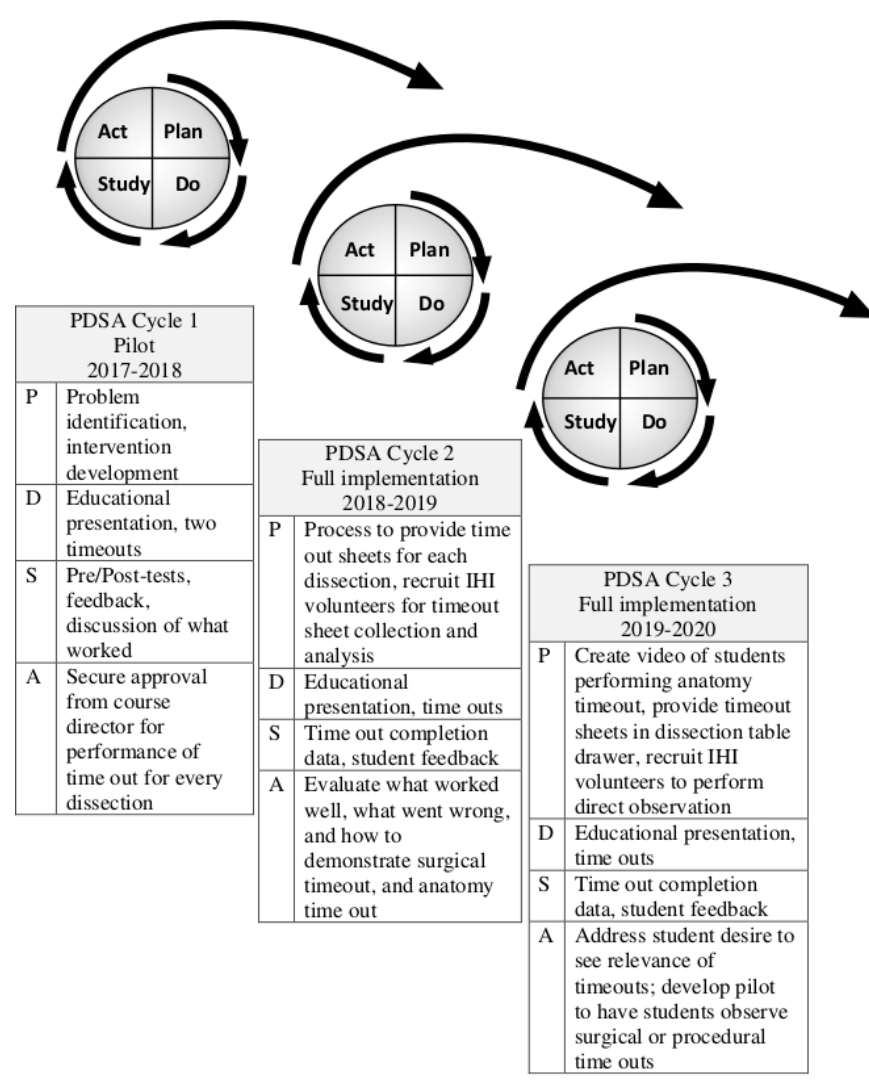

Figure 1 Development of anatomy time out intervention using rolling Deming PDSA cycle design. IHI, Institute for Healthcare Improvement; PDSA, Plan-Do-Study-Act.

our Institute for Healthcare Improvement (IHI) chapter collaborated with faculty to develop an intervention to introduce the surgical time out into the gross anatomy course. Using a quality improvement approach with PlanDo-Study-Act (PDSA) methodology (figure 1), we fully implemented surgical time outs prior to each anatomy dissection. During academic year 2017-2018, first year medical students at Wayne State University School of Medicine (WSUSOM) completed surgical time outs prior to two dissections during the gross anatomy course, which consisted of 30 total dissections. The surgical time out used was adapted from the universal protocol and surgical safety checklists provided by the WHO. ${ }^{9}$ These checklists have categories for different stages of the procedure including before anaesthesia in the preoperative holding areas, before the first incision and before the patient leaves the operating room for postoperative care. We adapted these checklists so that the entire surgical time out could be completed prior to beginning the dissection (see section 1 of online supplemental appendix).

Before the first session in the gross anatomy lab, students completed a preintervention survey. The survey evaluated four domains including student's understanding of (1) the major components, goals and limitations of universal protocol, (2) the medical error lexicon (eg, 'neverevents', 'surgical time out'), (3) the components of a presurgical time out, and (4) confidence in completing a presurgical time out checklist which consisted of nine questions (table 1).

After the preintervention survey was completed, a physician facilitator delivered a 30 min presentation explaining medical errors, the universal protocol and the surgical time out procedure. Students were shown a video from the television show, "ER" demonstrating a surgical time out.

\section{Table 1 Survey questions by domain}

\begin{tabular}{ll} 
Domain & Question \\
\hline Student's understanding of the major & 1. What are the major components of the universal protocol? \\
components, goals and limitations of universal & 2. What are the goals of the universal protocol? \\
protocol & 3. Which of the following has become a major limitation in the \\
& implementation of universal protocol? \\
& A. Expansion of the time out beyond the scope of its purpose. \\
& B. Amount of time needed to complete the procedure. \\
C. Unclean surgical instrumentation.
\end{tabular}

\section{Student's understanding of the medical error} lexicon (eg, 'never-events', 'surgical time out')

\section{Student's understanding of the components of a 5 . What are the minimum components of a surgical time out?} presurgical time out

Student's comfort in completing a presurgical time 6a. Indicate your level of agreement with the following statement: out checklist
Completing a time out procedure is easy to accomplish.

$6 \mathrm{~b}$. Indicate your level of agreement with the following statement: I have a clear understanding of the elements of a procedural time out.

6c. Indicate your level of agreement with the following statement: I am confident performing a procedural time out.

$6 \mathrm{~d}$. Indicate your level of agreement with the following statement: I think that students should perform a procedural time out prior to every dissection. 
During the first lab session of the year, students obtained a time out form from an envelope posted next to the doorway of the anatomy lab. Students then completed the surgical time out with their dissection team using the adapted WHO time out form. Students completed one sheet per dissection team. Dissection teams consisted of six medical students. Students confirmed the patient's identity by recording the cadaver's identification number, sex and assigned dissection table number. Then, students confirmed and noted the procedure ('dissection') to be performed and the route to be used. Any anticipated critical events (eg, broken scalpel blade) were documented. Students recorded the start and end time for the time out. In order to mimic a surgical scenario, students noted if a consent form was signed by the patient or surrogate. Students were told consent was obtained for dissection at the time of body donation and recorded 'yes' on the form. Students then marked the site of the procedure on the cadaver. Lastly, students noted if the instruments to be used were adequate, if any necessary devices were available and functional and if essential imaging was displayed. After the time out was completed, all team members initialled the form to signify that the surgical time out was completed and that all team members participated. The time out form was then placed in a collection envelope at the doorway of the lab.

The day after the first lab, students were sent a postintervention survey (postintervention survey 1 ) with the same questions as the preintervention survey. During the final anatomy lab, a second surgical time out was conducted, followed by a final postintervention survey (postintervention survey 2) containing only questions from the preintervention and postintervention 1 surveys assessing student's comfort in completing a presurgical time out checklist. After the final anatomy lab, students were offered an opportunity to observe a surgical time out at Detroit Receiving Hospital, one of the clinical sites for WSUSOM students.

With feasibility demonstrated, in the 2018-2019 school year, we modified the intervention. First year medical students were instructed to complete surgical time outs prior to each dissection throughout the school year. They received the presentation explaining medical errors, the universal protocol and the surgical time out. However, no preintervention survey or postintervention survey was administered. Students were told participation was required but no consequences were defined. We collected time out sheets at the end of each dissection and recorded the number of time outs that were completed for each dissection to assess participation. Student feedback regarding the time outs was collected by IHI volunteers. Students indicated they wanted to see a surgical time out rather than a television depiction.

For the 2019-2020 school year, students from the board of our IHI group video recorded a time out in the anatomy lab to model a student time out. This was viewed by the class as part of the educational presentation prior to the first anatomy dissection. A surgical time out was located from YouTube and presented as well. Students from the IHI chapter who developed the intervention answered questions about the time out procedure. Time out sheets were placed in each group's cadaver table storage drawer as well as in an envelope in the doorway of the lab to prevent a potential shortage of time out documents. Finally, clinical faculty and members of the IHI group observed students performing the first time out of the year and once again at the midpoint to ensure that they were being performed appropriately.

For the analysis, per cent correct on the preintervention and postintervention survey 1 was calculated by the number of students who answered a question correctly divided by the number of students who completed the question. For completion rates of time out sheets, we divided the number of time out sheets by the total number of dissection teams. The average completion time for the time out checklist was calculated by taking the average of students' responses to the question 'How many minutes did it take your table to complete the procedural time out?'. To analyse our outcome data, we conducted a paired samples t-test to compare means between our preintervention and postintervention survey 1. We compared means by question item, domain sum and complete survey sum. We conducted our analysis using SPSS V.25.0 for Macintosh.

\section{Patient and public involvement}

Patients or the public were not involved in the design, or conduct, or reporting, or dissemination plans of our research.

\section{RESULTS}

\section{First PDSA pilot intervention (2017-2018)}

The preintervention survey was completed by 279 of 306 $(91 \%)$ students; 306 students participated in the first time out and 300 students submitted the time out form (98\%). The average completion time for the time out checklist was 2.8 min with an SD of $1.77 \mathrm{~min}$. Two hundred and sixteen $(71 \%)$ students completed postintervention survey 1 and 249 (81\%) completed postintervention survey 2.

\section{Preintervention, postintervention 1 and postintervention 2 survey} results

The results of our preintervention, postintervention 1 and postintervention 2 surveys are summarised in table 2 .

\section{Second PDSA (2018-2019)}

On average, $91.1 \%$ of 51 dissection teams completed a time out for every dissection. Of the 30 sessions of gross anatomy lab, only two sessions had participation below $80 \%$. On review, we learnt that on these 2 days there were inadequate quantities of the time out forms. Students asked for additional forms, but forms were not immediately available. 
Table 2 Results of preintervention and postintervention 1 surveys

\begin{tabular}{|c|c|c|c|c|c|c|c|}
\hline \multirow[b]{2}{*}{ Domain } & \multirow[b]{2}{*}{ Question } & \multirow{2}{*}{$\frac{\text { Preintervention }}{\mathrm{n} \text { (\%corr) }}$} & \multirow{2}{*}{$\begin{array}{l}\text { Postintervention } 1 \\
\text { n (\%corr) }\end{array}$} & \multirow{2}{*}{$\begin{array}{l}\text { Postintervention } 2 \\
\text { n (\%corr) }\end{array}$} & \multicolumn{2}{|c|}{$\begin{array}{l}\text { Descriptive statistics* } \\
\text { (PT; PTT1) }\end{array}$} & \multirow{2}{*}{$\begin{array}{l}\text { Paired differences* } \\
\text { (PT; PTT1) } \\
\text { Significance (two } \\
\text { tailed) }\end{array}$} \\
\hline & & & & & Mean & SD & \\
\hline \multirow[t]{4}{*}{1} & 1 & 277 (54.5) & $216(97.7)$ & $\mathrm{n} / \mathrm{a}$ & $\begin{array}{l}0.59 \\
0.98\end{array}$ & $\begin{array}{l}0.49 \\
0.15\end{array}$ & $6.5024 \mathrm{E}-22$ \\
\hline & 2 & $278(88.1)$ & $216(100.0)$ & $\mathrm{n} / \mathrm{a}$ & $\begin{array}{l}0.92 \\
1.00\end{array}$ & $\begin{array}{l}0.28 \\
0.00\end{array}$ & 0.000016 \\
\hline & 4 & 278 (35.6) & 216 (50.9) & $\mathrm{n} / \mathrm{a}$ & $\begin{array}{l}0.34 \\
0.51\end{array}$ & $\begin{array}{l}0.47 \\
0.50\end{array}$ & 0.000296 \\
\hline & Sum & $\mathrm{n} / \mathrm{a}$ & $\mathrm{n} / \mathrm{a}$ & $\mathrm{n} / \mathrm{a}$ & $\begin{array}{l}0.62 \\
0.83\end{array}$ & $\begin{array}{l}0.27 \\
0.17\end{array}$ & $3.0212 \mathrm{E}-19$ \\
\hline 2 & 3 & 278 (76.3) & $216(97.7)$ & $\mathrm{n} / \mathrm{a}$ & $\begin{array}{l}0.81 \\
0.98\end{array}$ & $\begin{array}{l}0.40 \\
0.15\end{array}$ & $2.4865 \mathrm{E}-8$ \\
\hline 3 & 5 & $278(74.1)$ & 216 (91.7) & $\mathrm{n} / \mathrm{a}$ & $\begin{array}{l}0.80 \\
0.92\end{array}$ & $\begin{array}{l}0.40 \\
0.28\end{array}$ & 0.000223 \\
\hline \multirow[t]{5}{*}{4} & $6 a$ & 279 & 215 & 248 & $\begin{array}{l}3.47 \\
4.50\end{array}$ & $\begin{array}{l}0.75 \\
0.70\end{array}$ & $2.9153 \mathrm{E}-35$ \\
\hline & $6 b$ & 279 & 213 & 246 & $\begin{array}{l}2.30 \\
4.34\end{array}$ & $\begin{array}{l}1.09 \\
0.77\end{array}$ & 4.167E-57 \\
\hline & $6 c$ & 278 & 213 & 249 & $\begin{array}{l}2.27 \\
4.32\end{array}$ & $\begin{array}{l}1.06 \\
0.79\end{array}$ & $2.3818 \mathrm{E}-58$ \\
\hline & $6 d$ & 276 & 215 & 249 & $\begin{array}{l}3.69 \\
4.11\end{array}$ & $\begin{array}{l}0.78 \\
0.97\end{array}$ & 0.000001 \\
\hline & Sum & $\mathrm{n} / \mathrm{a}$ & $\mathrm{n} / \mathrm{a}$ & $\mathrm{n} / \mathrm{a}$ & $\begin{array}{l}0.59 \\
0.86\end{array}$ & $\begin{array}{l}0.13 \\
0.14\end{array}$ & $1.0785 \mathrm{E}-53$ \\
\hline Test & Sum & $\mathrm{n} / \mathrm{a}$ & $\mathrm{n} / \mathrm{a}$ & $\mathrm{n} / \mathrm{a}$ & $\begin{array}{l}0.68 \\
0.87\end{array}$ & $\begin{array}{l}0.19 \\
0.10\end{array}$ & $2.4165 \mathrm{E}-29$ \\
\hline
\end{tabular}

${ }^{*}$ Descriptive statistics and paired differences analysis were done comparing preintervention and postintervention 1 only.

\%corr, per cent correct; n/a, not applicable; PT, preintervention survey; PTT1, postintervention survey 1.;

Third PDSA (2019-2020)

Students continued to complete time outs with an average completion rate of $97.4 \%$.

\section{DISCUSSION}

Our results suggest that our educational intervention was effective in improving student's knowledge and understanding regarding surgical time outs, ability to perform time outs and confidence performing time outs. This is evidenced by the fact that there was significant improvement in performance of medical students on the postintervention survey 1 . Notably, less participants completed the postintervention survey as compared with the preintervention survey. This is likely due to the fact that the preintervention survey was assigned to be completed prior to the presentation on the topic. Instructions to complete the postintervention survey 1 were sent out after the event and no mechanism was established to confirm that all students completed the survey as the survey was anonymous. Nearly half of students reported that their anatomy groups performed surgical time outs in-between their first and last required time out experiences, demonstrating students practised patient safety even when not instructed to. During our second PDSA cycle the following year, nearly every lab group completed a surgical time out at the beginning of every lab despite absence of consequences for lack of completion. Findings of the three PDSAs indicate that completing at least one time out during anatomy lab improves students' perceptions of their understanding of the components, ease of completing and confidence in completing a time out. Furthermore, data from the second and third PDSA cycles suggest that students practise QIPS and complete time outs every session even when not observed, prompted or penalised. We believe that this experience promoted a culture change among students as it relates to completing surgical checklists to avoid medical error.

\section{CONCLUSION}

Through the incorporation of surgical time outs into the first-year anatomy course, we have shown that training medical students to perform time outs is feasible. Students found the time outs easy to complete and they developed the confidence and ability to perform a surgical time out early in their medical education. Finally, students performed these time outs when not observed 
and without course penalty. The new skills, knowledge and attitudes that these medical students have developed will hopefully improve the care they provide to patients, thereby advancing the practice of QIPS in the clinical setting.

Author affiliations

${ }^{1}$ Wayne State University School of Medicine, Detroit, Michigan, USA

${ }^{2}$ Department of Ophthalmology, Visual and Anatomical Sciences, Wayne State

University School of Medicine, Detroit, Michigan, USA

${ }^{3}$ Department of Internal Medicine, Wayne State University, Detroit, Michigan, USA

Twitter Diane Levine @DianeLevine1

Acknowledgements The authors thank Dr Lea Monday for allowing them to use her PDSA figure. The authors also thank the Institute for Healthcare Improvement's student group at the Wayne State University School of Medicine for their support in conducting this project.

Contributors ARMS collected and analysed the data, drafted the results and discussion section, compiled the manuscript, and heavily edited and submitted the manuscript. DA collected the data, drafted the initial introduction and edited the manuscript. PK collected the data, drafted the method section and edited the manuscript. JV collected the data, drafted the conclusion and edited the manuscript. JH collected the data and edited the manuscript. KE made the literature review, drafted part of the discussion and edited the manuscript. PW assisted with the logistics and design of the project, and edited the manuscript. DL designed the study, heavily edited the manuscript and assisted with data analysis.

Funding The authors have not declared a specific grant for this research from any funding agency in the public, commercial or not-for-profit sectors.

Competing interests None declared.

Patient consent for publication Not required.

Ethics approval The project was reviewed by the Institutional Review Board (IRB) and they determined that it did not constitute human participant research according to the definition codified in the Common Rule at 45 Code of Federal Regulations Part 46 and the Food and Drug Administration regulations and therefore no IRB review and oversight was required.

Provenance and peer review Not commissioned; externally peer reviewed.

Data availability statement All data relevant to the study are included in the article.
Supplemental material This content has been supplied by the author(s). It has not been vetted by BMJ Publishing Group Limited (BMJ) and may not have been peer-reviewed. Any opinions or recommendations discussed are solely those of the author(s) and are not endorsed by BMJ. BMJ disclaims all liability and responsibility arising from any reliance placed on the content. Where the content includes any translated material, BMJ does not warrant the accuracy and reliability of the translations (including but not limited to local regulations, clinical guidelines, terminology, drug names and drug dosages), and is not responsible for any error and/or omissions arising from translation and adaptation or otherwise.

Open access This is an open access article distributed in accordance with the Creative Commons Attribution Non Commercial (CC BY-NC 4.0) license, which permits others to distribute, remix, adapt, build upon this work non-commercially, and license their derivative works on different terms, provided the original work is properly cited, appropriate credit is given, any changes made indicated, and the use is non-commercial. See: http://creativecommons.org/licenses/by-nc/4.0/.

ORCID iD

Abdul-Rahman M Suleiman http://orcid.org/0000-0002-4540-4741

\section{REFERENCES}

1 Makary MA, Daniel M. Medical error-the third leading cause of death in the US. BMJ 2016;353:i2139.

2 Jung JJ, Elfassy J, Jüni $P$, et al. Adverse events in the operating room: definitions, prevalence, and characteristics. A systematic review. World J Surg 2019;43:2379-92.

3 Mehtsun WT, Ibrahim AM, Diener-West M, et al. Surgical never events in the United States. Surgery 2013;153:465-72.

4 Berry WR, Edmondson L, Gibbons LR, et al. Scaling safety: the South Carolina surgical safety checklist experience. Health Aff 2018;37:1779-86.

5 Schwendimann R, Blatter C, Lüthy M, et al. Adherence to the who surgical safety checklist: an observational study in a Swiss academic center. Patient Saf Surg 2019;13:14.

6 Gillespie BM, Marshall A. Implementation of safety checklists in surgery: a realist synthesis of evidence. Implement Sci 2015;10:137.

7 AAMC. Teaching for quality: integrating quality improvement and patient safety across the continuum of medical education 2013.

8 AAMC. Quality Improvement and Patient Safety Competencies Across the Learning Continuum. AAMC New and Emerging Areas in Medicine Series. Washington, DC: AAMC, 2019.

9 Haynes AB, Weiser TG, Berry WR, et al. A surgical safety checklist to reduce morbidity and mortality in a global population. $N$ Engl $\mathrm{J}$ Med Overseas Ed 2009;360:491-9. 